\title{
Trends of Non-Accidental, Cardiovascular, Stroke and Lung Cancer Mortality in Arkansas Are Associated with Ambient $\mathbf{P M}_{2.5}$ Reductions
}

\author{
Marie-Cecile G. Chalbot, Tamara A. Jones and Ilias G. Kavouras * \\ Department of Environmental and Occupational Health, College of Public Health, University of Arkansas \\ for Medical Sciences, Little Rock, AR 72205, USA; E-Mails: mchalbot@uams.edu (M.-C.G.C.); \\ misstiat94@yahoo.com (T.A.J.)
}

* Author to whom correspondence should be addressed; E-Mail: ikavouras@ uams.edu; Tel.: +1-501-526-6627; Fax: +1-501-526-6507.

Received: 23 November 2013; in revised form: 12 March 2014 / Accepted: 13 March 2014 / Published: 21 July 2014

\begin{abstract}
The cardiovascular and stroke mortality rates in Arkansas are among the highest in the USA. The annual trends of stroke and cardiovascular mortality are barely correlated to smoking cessation; while the prevalence of risk factors such as obesity; cholesterol and hypertension increased over the 1979-2007 period. The study determined the effect of chronic exposure to $\mathrm{PM}_{2.5}$ on non-accidental; cardiovascular; stroke and lung cancer mortality in Arkansas over the 2000-2010 period using the World Health Organization's log-linear health impact model. County chronic exposures to $\mathrm{PM}_{2.5}$ were computed by averaging spatially-resolved gridded concentrations using $\mathrm{PM}_{2.5}$ observations. A spatial uniformity was observed for $\mathrm{PM}_{2.5}$ mass levels indicating that chronic exposures were comparable throughout the state. The reduction of $\mathrm{PM}_{2.5}$ mass levels by $3.0 \mu \mathrm{g} / \mathrm{m}^{3}$ between 2000 and 2010 explained a significant fraction of the declining mortality. The effect was more pronounced in southern and eastern rural Arkansas as compared to the rest of the state. This study provides evidence that the implementation of air pollution regulations has measurable effects on mortality even in regions with high prevalence of major risk factors such as obesity and smoking. These outcomes are noteworthy as efforts to modify the major risk factors require longer realization times.
\end{abstract}

Keywords: air pollution; fine particles; annual trends; spatial variation; urban aerosol 


\section{Introduction}

The southeast region of the USA has been historically identified as the "stroke belt" but more recently, the existence of a "heart failure belt" was also observed in the same region [1,2]. Arkansas has the highest age-adjusted stroke mortality in the USA and ranked among the top five states for heart disease mortality. The 2005-2009 age-adjusted mortality rates for heart disease and stroke was higher among African-Americans than for whites and Hispanics [3]. Heart disease and stroke mortality rates were higher in rural communities in eastern Arkansas along the Mississippi Delta region as compared to the urbanized areas in central and northwest Arkansas. Deaths from heart diseases and stroke have been decreasing over the past 20 years [3]; however, the prevalence of major risk factors such as obesity, high blood pressure and cholesterol increased [4]. Changes in smoking habits were associated with long-term trends of mortality rates but did not justify the observed racial and geographical disparities in southeast USA [4,5]. The anticipated improvements of increased awareness, new drugs and therapies did not materialize shortly after their implementation [4].

Owing to the absence of major industrial facilities, scarcely populated urban areas and frequent precipitation scavenging, the impacts of atmospheric particulate pollution on cardiovascular and stroke mortality received very little attention, if any, in this region. Meanwhile, epidemiological studies showed consistent, strong and statistically significant associations between $\mathrm{PM}_{2.5}$ (fine particles with aerodynamic diameter less than $2.5 \mu \mathrm{m}$ ) and cardiovascular, stroke and respiratory mortality and morbidity in the USA and around the world [6-12]. Recent studies showed that the risk of stroke may increase up to $34 \%$ even at low $\mathrm{PM}_{2.5}$ levels in New England [13]. These levels were comparable or lower to those typically measured in Arkansas [14]. Secondary sulfate and nitrate, biomass combustion, traffic and diesel particles were identified as the most important particle types and sources of $\mathrm{PM}_{2.5}$ in Arkansas, which is typical to those observed in eastern USA [14-16]. Emissions of pollutants from energy-related sources (i.e., volatile organic compounds and nitrogen oxides) from upwind regions (oil/natural gas exploration and refineries in the Gulf of Mexico, Houston, TX, USA) were significant determinants of $\mathrm{PM}_{2.5}$ levels in Arkansas. Previous studies showed that transport of volatile organic compounds and nitrogen oxides from southeast USA along the Gulf Coast yielded very high ozone $\left(\mathrm{O}_{3}\right)$ concentration along the Mississippi Valley to the Great Lakes and Upper Midwest region [17].

The overarching aim of this study was to determine the burden of chronic exposures to $\mathrm{PM}_{2.5}$ on non-accidental, cardiovascular, stroke and lung cancer mortality in the state of Arkansas over the 2000-2010 period. We achieved this by using the World Health Organization's (WHO) health impacts analysis (HIA) methodology [18-22]. Estimates of the $\mathrm{PM}_{2.5}$ concentrations, the annual trends, spatiotemporal variability and county-average $\mathrm{PM}_{2.5}$ mass concentrations were computed using $\mathrm{PM}_{2.5}$ measurements in multiple locations.

\section{Methods}

\subsection{Health Impacts Assessment}

We obtained county-based data for non-accidental, cardiovascular (ICD-10 codes: 410-429), stroke (ICD-10 codes: 430-438) and lung cancer (ICD-10 code: 162) mortality from the Arkansas's 
Department of Health Indicator Based Information System for Public Health. The 2000 and 2010 population counts of $30+$ years old for each county were obtained from USA Census.

The effects of changes in $\mathrm{PM}_{2.5}$ between 2000 and 2010 were assessed by calculating the change in the number of deaths (Y, in Equation (1)) in 2010 for each county where $\mathrm{P}$ is the 2010 population in each county, $\mathrm{b}$ is the 2000 mortality rate (per 100,000), $\beta$ is the effect coefficient per a $1 \mu \mathrm{g} / \mathrm{m}^{3}$ increase of $\mathrm{PM}_{2.5}$ mass, and $\Delta\left(\mathrm{PM}_{2.5}\right)$ is the change in $\mathrm{PM}_{2.5}$ mass between 2001 and 2010 [18-20]:

$$
Y=(P / 100,000) \times b \times\left(e^{\beta \cdot \Delta\left(\mathrm{PM}_{2.5}\right)}-1\right)
$$

The $\beta$ values for non-accidental (1.06; 95\% CI: 1.02-1.11), lung cancer (1.14; 95\% CI: $1.04-1.23)$ and cardiovascular (1.09; 95\% CI: 1.03-1.06) mortality were obtained from the American Cancer Society (ACS) study, a long-term cohort study examining the impacts of air pollution on mortality [23-25]. The relative risk of $\mathrm{PM}_{2.5}$-induced stroke mortality (1.03; 95\% CI: 0.02-2.04) were obtained from the analysis of the associations between $\mathrm{PM}_{2.5}$ and mortality in 27 USA communities including Birmingham, Alabama and Memphis, Tennessee, two urban areas with similar demographic characteristics to Arkansas urban areas [26].

The $\mathrm{PM}_{2.5}$-resultant change in mortality between 2000 and 2010 (Y in Equation (1)) was then compared to the actual change in mortality between 2000 and 2010 and the percentage effect of $\mathrm{PM}_{2.5}$-resultant mortality on observed mortality $(\Delta \mathrm{M})$ was calculated as follows:

$$
\Delta \mathrm{M}=\left(\frac{\mathrm{Y}}{\text { Deaths }_{2010}-\text { Deaths }_{2000}}\right) \times 100
$$

where Deaths 2000 and Deaths 2010 were the number of non-accidental, cardiovascular, stroke and lung cancer deaths in 2000 and 2010, respectively. Because of the observed declining trend of $\mathrm{PM}_{2.5}$, a reduction in mortality was anticipated. Thus, positive $\Delta \mathrm{M}$ values indicated the magnitude of the reduction of $\mathrm{PM}_{2.5}$-resultant deaths to the overall reduction of deaths, while, negative values showed that the actual number of deaths increased between 2000 and 2010. $\Delta \mathrm{M}>1$ (or 100\%) suggested that the actual reduction in deaths was lower than the estimated reduction due to $\mathrm{PM}_{2.5}$ declining levels.

\section{2. $P M_{2.5}$ Mass Concentrations}

The measured $\mathrm{PM}_{2.5}$ mass concentrations in eighteen (18) sites in the state of Arkansas during the 2000-2011 timespan were retrieved from EPA's Air Quality System (AQS). Figure 1 shows the locations of the monitoring sites in the state including those in the Little Rock/North Little Rock metropolitan statistical area (ar11, ar11 and ar12 in Figure 1). Sixteen sites including the NCore site (ar10; AQS \#05-119-0007; a site that integrates advanced measurement for particles, pollutant gases and meteorology), are operated by the Arkansas Department of Environmental Quality. Monthly mean $\mathrm{PM}_{2.5}$ concentrations were computed for periods with more than $75 \%$ valid measurements (22 days/month for daily measurements and 7 days/month for 1-in-3 measurement frequency). The monthly 24-h mean $\mathrm{PM}_{2.5}$ mass concentration was computed for months with more than 75 percent valid estimates of daily $\mathrm{PM}_{2.5}$ mass concentrations. The annual trend of $\mathrm{PM}_{2.5}$ mass in each site was computed by ordinary least squares regression analysis of deseasonalized monthly mean 
$\mathrm{PM}_{2.5}$ mass concentrations using the "Census I" method integrated in SPSS [14,27]. Missing monthly averages was replaced by average concentration of the same month over the 2000-2010 period introducing an error of up to $1.6 \%$ for $10 \%$ missing values (no more than $10 \%$ of missing values were observed in our dataset).

Figure 1. The locations of the $\mathrm{PM}_{2.5}$ monitoring sites in Arkansas.

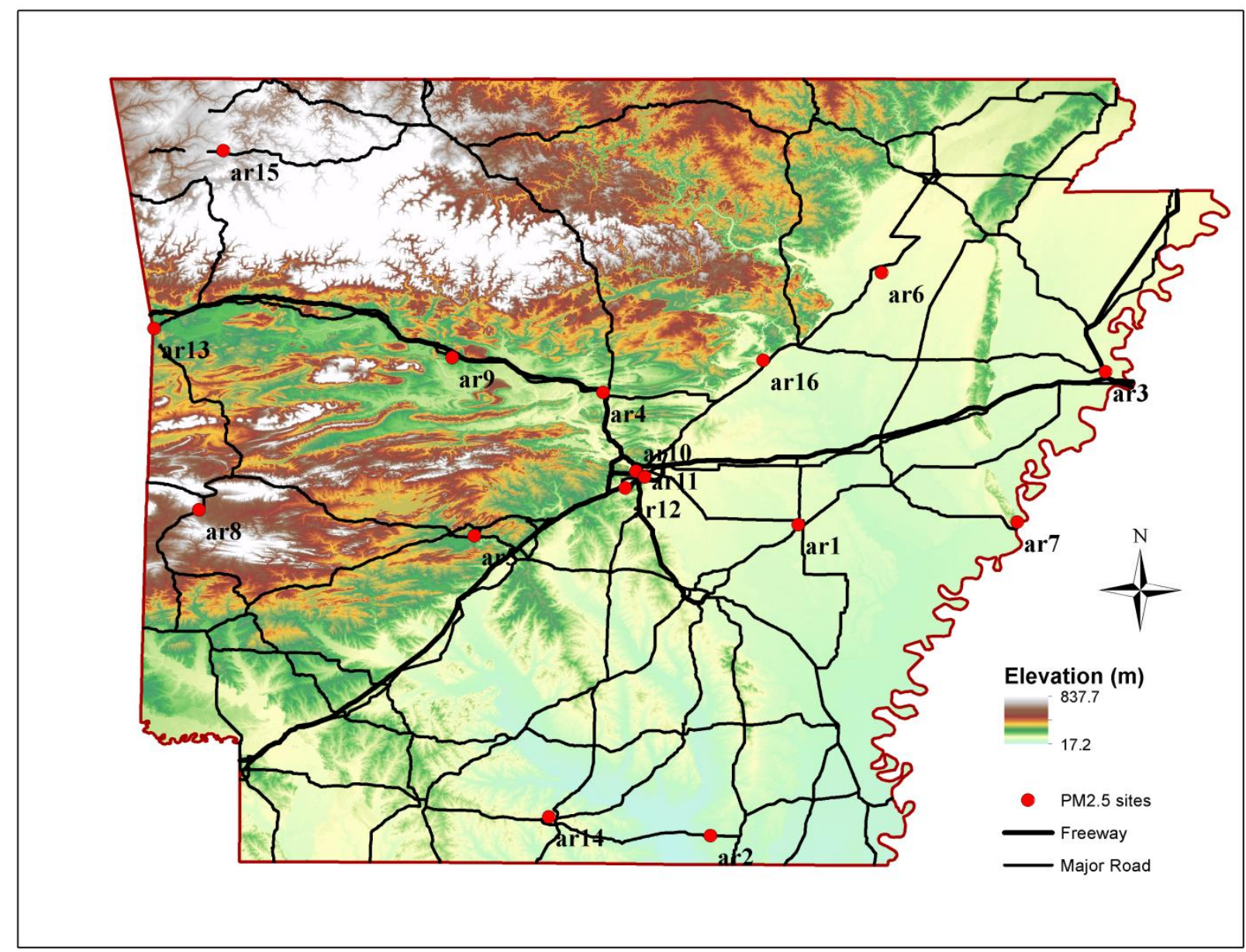

The absolute $(\Delta \mathrm{C})$ and the relative $(\% \Delta \mathrm{C} / \mathrm{Ref})$ differences of daily $\mathrm{PM}_{2.5}$ mass concentrations between two sites were computed to evaluate concentration gradients in the region [28,29]. The $\mathrm{PM}_{2.5}$ monitor at the NCore site was the reference site because was centrally located to the study region, had the most complete $\mathrm{PM}_{2.5}$ dataset and detailed data of $\mathrm{PM}_{2.5}$ chemical content and other criteria air pollutants were also available. The relative concentration differences were computed as the percentage of the absolute concentration difference to the reference site concentration. Positive values indicate that $\mathrm{PM}_{2.5}$ concentrations at the site were higher than those measured at the NCore site. The coefficient of divergence (COD) was used to assess the spatial uniformity of measurements with respect to the concentration levels (Equation (3)) [28,29].

$$
\mathrm{COD}=\sqrt{\frac{1}{\mathrm{n}} \cdot \sum_{\mathrm{i}=1}^{\mathrm{n}}\left(\frac{\mathrm{C}_{\mathrm{ij}}-\mathrm{C}_{\mathrm{ik}}}{\mathrm{C}_{\mathrm{ij}}+\mathrm{C}_{\mathrm{ik}}}\right)^{2}}
$$


where $n$ is the total number of paired measurements, and $\mathrm{C}_{i j}$ and $\mathrm{C}_{i k}$ are the measured concentrations at the reference and comparison sites on the $i$-th month, respectively. COD values vary from 0 to 1 , with COD values close to unity being suggestive of strong spatial variation [28,29].

The mean annual $\mathrm{PM}_{2.5}$ mass concentration for each county was computed by calculating the average of annual $\mathrm{PM}_{2.5}$ mass concentration for $0.2^{\circ} \times 0.2^{\circ}$ using kriging and accounting for elevation boundaries and restrictions in ArcMAP (Version 10.0, ESRI, Redlands, CA, USA) [30-32].

\section{Results}

\subsection{PM 2.5 Annual and Spatial Trends}

Table 1 presents the mean and standard deviation $(\sigma)$ of the $\mathrm{PM}_{2.5}$ mass concentrations during the study period, the annual $\mathrm{PM}_{2.5}$ trend ( \pm standard error (s)), the median and $\sigma$ of absolute and relative concentration differences and the mean $( \pm \mathrm{s}) \mathrm{COD}$ value for each of the 18 sites. The mean $\mathrm{PM}_{2.5}$ mass levels demonstrated very little spatial variability, from 11.0 to $13.2 \mu \mathrm{g} / \mathrm{m}^{3}$. The highest mean $\mathrm{PM}_{2.5}$ mass was measured in the Little Rock/North Little Rock sites (ar10, ar11 and ar12) and nearby populated regions, from 12.0 to $13.2 \mu \mathrm{g} / \mathrm{m}^{3}$ (ar4 site in Conway and ar9 site in Russellville) followed by $\mathrm{PM}_{2.5}$ levels measured in the West Memphis area (ar3). The lowest $\mathrm{PM}_{2.5}$ levels in populated areas were measured in the southwest (ar8) and northwest (ar15) regions.

Table 1. The $\mathrm{PM}_{2.5}$ annual trends (mean \pm st.error), absolute $(\Delta \mathrm{C})$ and relative $(\% \Delta \mathrm{C} / \mathrm{Ref})$ concentration differences (compared to the "ar10" site) and the COD ratio (mean \pm standard error) in Arkansas monitoring sites.

\begin{tabular}{|c|c|c|c|c|c|c|}
\hline \multirow{2}{*}{ Site } & \multirow{2}{*}{$\begin{array}{c}\text { Annual Trend } \\
\left(\mu \mathrm{g} / \mathrm{m}^{3} / \text { year }\right)\end{array}$} & \multicolumn{2}{|c|}{$\Delta \mathrm{C}$} & \multicolumn{2}{|c|}{$\% \Delta \mathrm{C} / \mathrm{Ref}$} & \multirow{2}{*}{ COD } \\
\hline & & Median & $S D$ & Median & $S D$ & \\
\hline $\operatorname{ar1}$ & $-0.3 \pm 0.5$ & -0.9 & 3.5 & -8.1 & 74.5 & $0.19 \pm 0.02$ \\
\hline $\operatorname{ar1}$ & $-0.5 \pm 0.6$ & -1.0 & 4.8 & -8.2 & 122.8 & $0.19 \pm 0.03$ \\
\hline $\operatorname{ar} 3$ & $-0.4 \pm 0.5$ & -0.5 & 4.4 & -4.4 & 83.5 & $0.18 \pm 0.01$ \\
\hline $\operatorname{ar} 4$ & $-0.3 \pm 0.5$ & -0.7 & 3.1 & -6.2 & 103.5 & $0.19 \pm 0.03$ \\
\hline $\operatorname{ar5}$ & $-0.2 \pm 0.5$ & -1.0 & 3.4 & -9.3 & 31.7 & $0.20 \pm 0.04$ \\
\hline ar6 & $-0.2 \pm 1.0$ & -1.1 & 4.5 & -10.3 & 120.3 & $0.22 \pm 0.05$ \\
\hline $\operatorname{ar} 7$ & $-0.3 \pm 0.6$ & -1.1 & 4.5 & -9.1 & 87.8 & $0.20 \pm 0.04$ \\
\hline ar8 & $-0.1 \pm 0.3$ & -1.5 & 4.4 & -13.4 & 109.9 & $0.21 \pm 0.06$ \\
\hline $\operatorname{ar9}$ & $-0.2 \pm 0.4$ & -0.7 & 4.0 & -5.9 & 36.3 & $0.18 \pm 0.01$ \\
\hline $\operatorname{ar10}$ & $-0.3 \pm 0.4$ & - & - & - & - & - \\
\hline $\operatorname{ar11}$ & $-0.3 \pm 0.5$ & 0.3 & 3.0 & 2.5 & 88.7 & $0.16 \pm 0.01$ \\
\hline $\operatorname{ar12}$ & $-0.3 \pm 0.5$ & 0.1 & 2.7 & 1.3 & 58.3 & $0.16 \pm 0.01$ \\
\hline $\operatorname{ar13}$ & $-0.1 \pm 0.5$ & -0.7 & 4.4 & -6.9 & 127.5 & $0.19 \pm 0.03$ \\
\hline $\operatorname{ar14}$ & $-0.3 \pm 0.5$ & -0.6 & 4.6 & -5.7 & 134.0 & $0.18 \pm 0.04$ \\
\hline $\operatorname{ar} 15$ & $-0.2 \pm 0.3$ & -1.4 & 4.7 & -13.9 & 39.3 & $0.21 \pm 0.05$ \\
\hline $\operatorname{ar16}$ & $-0.3 \pm 0.5$ & -0.7 & 3.8 & -6.1 & 108.3 & $0.20 \pm 0.04$ \\
\hline
\end{tabular}

The highest absolute $(\Delta \mathrm{C})$ and relative $(\Delta \mathrm{C} / \mathrm{Ref})$ concentration differences varied from -1.1 (for ar6 and ar7 sites) to $0.3 \mu \mathrm{g} / \mathrm{m}^{3}$ (for ar11) and from $-13.9 \%$ to $2.5 \%$, respectively. The COD values for each site range from $0.16 \pm 0.00$ to $0.22 \pm 0.05$. For the two background sites, absolute and relative 
concentration differences were higher than those computed for the urban areas. $\mathrm{PM}_{2.5}$ decreased from $0.5 \pm 0.6$ to $0.1 \pm 0.3 \mu \mathrm{g} / \mathrm{m}^{3}$ per year with the highest declines in southern and eastern Arkansas (ar1, ar2, ar3 and ar7, Figure 1).

\subsection{Mortality Reductions}

Figure 2 shows the annual trends of mortality rates for non-accidental, cardiovascular, stroke and lung cancer mortality and the mean $\mathrm{PM}_{2.5}$ mass concentration in Arkansas. For all variables, a decreasing trend was observed, which was more pronounced for cardiovascular (about 21\%) and stroke mortality ( 30\%). Non-accidental mortality decreased by $7 \%$ between 2000 and 2010 with significant inter-annual variability that resembled that of lung cancer. For lung cancer, the mortality declined by only $2 \%$. The annual $\mathrm{PM}_{2.5}$ mass concentration in Arkansas decreased from $14.5 \mu \mathrm{g} / \mathrm{m}^{3}$ in 2000 to $11.5 \mu \mathrm{g} / \mathrm{m}^{3}$ in $2010(\sim 21 \%)$.

Figure 2. Annual trends of $\mathrm{PM}_{2.5}$ mass concentration, and non-accidental, cardiovascular, stroke and lung cancer mortality in Arkansas.

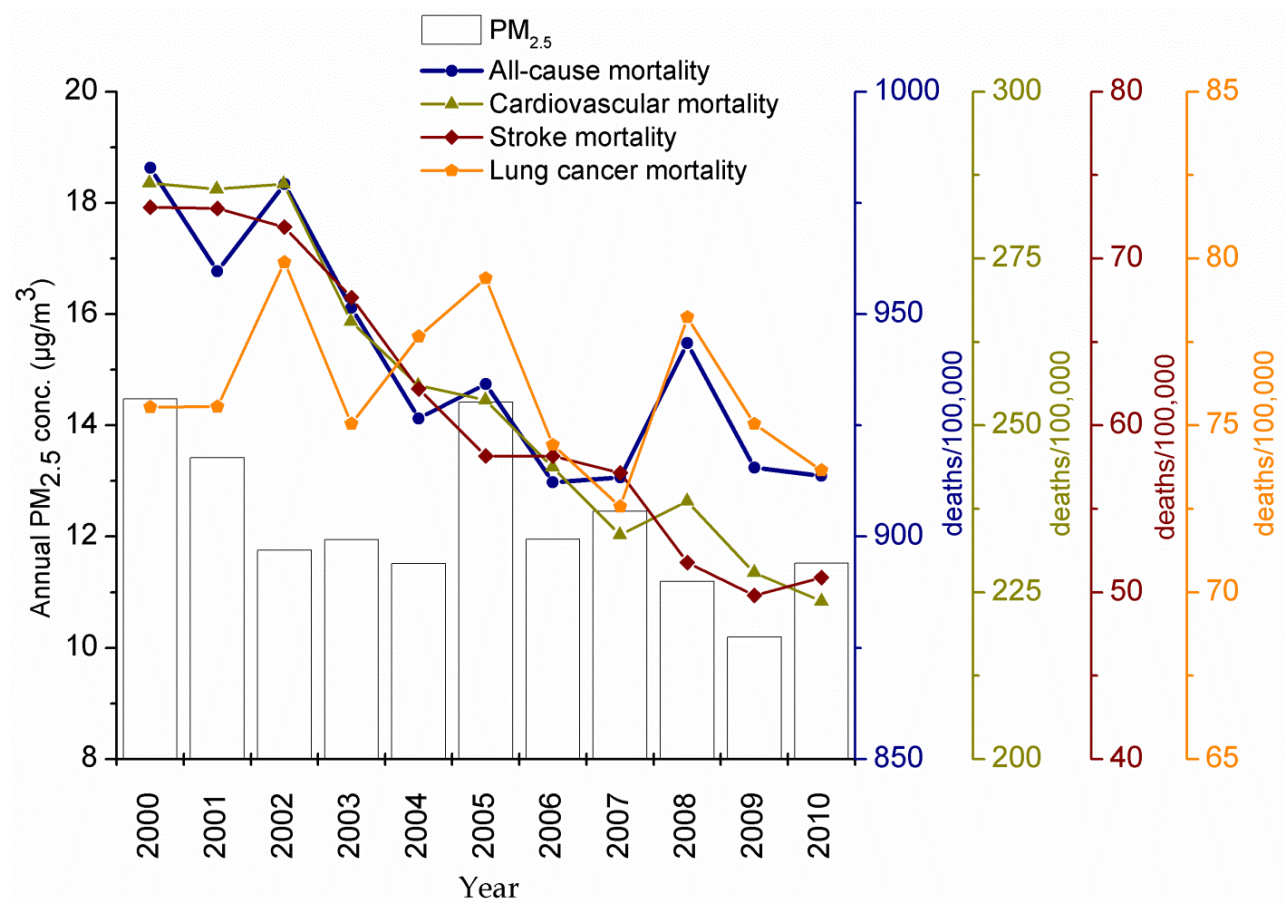

The percentage reductions of non-accidental, cardiovascular, stroke and lung cancer mortality attributed to reductions in $\mathrm{PM}_{2.5}$ mass concentrations per county in Arkansas are depicted in Figures 3-6 respectively. Out of the 75 counties, cardiovascular, stroke and lung cancer mortality increased in 13, 15 and 40 counties from 2000 to 2010, respectively, mostly in western and central Arkansas. For cardiovascular mortality, the reduction of $\mathrm{PM}_{2.5}$ in the Little Rock/North Little Rock, Jonesboro and Bentonville area fully accounted for the declining mortality rates. For rural Arkansas and the Delta region, up to $50 \%$ of reduced premature cardiovascular deaths was due to $\mathrm{PM}_{2.5}$ reductions. 
Figure 3. Percentage reduction of non-accidental mortality attributed to $\mathrm{PM}_{2.5}$ reductions for each Arkansas county.

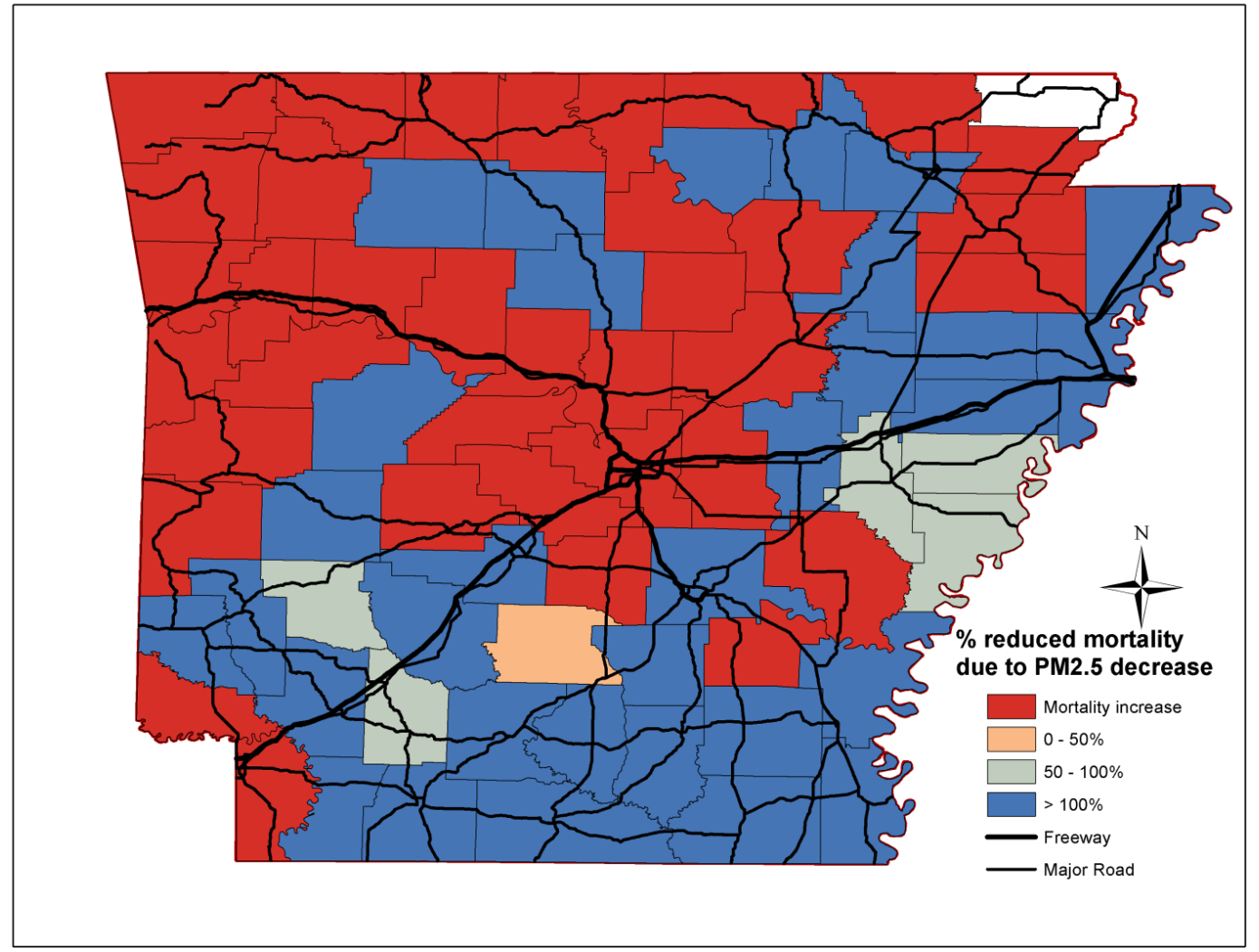

Figure 4. Percentage reduction of cardiovascular mortality attributed to $\mathrm{PM}_{2.5}$ reductions for each Arkansas county.




Figure 5. Percentage reduction of stroke mortality attributed to $\mathrm{PM}_{2.5}$ reductions for each Arkansas county.

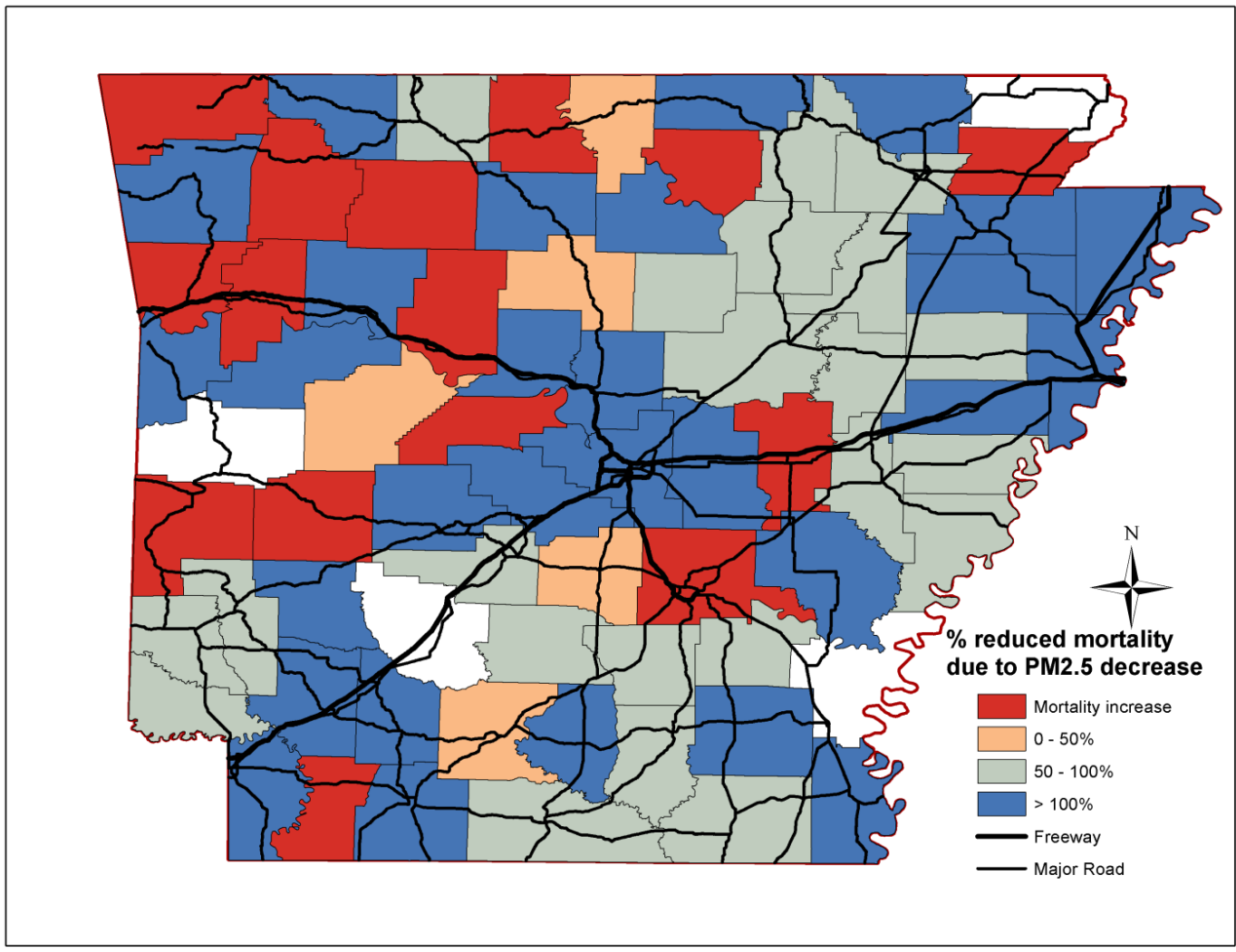

Figure 6. Percentage reduction of lung cancer mortality attributed to $\mathrm{PM}_{2.5}$ reductions for each Arkansas county.

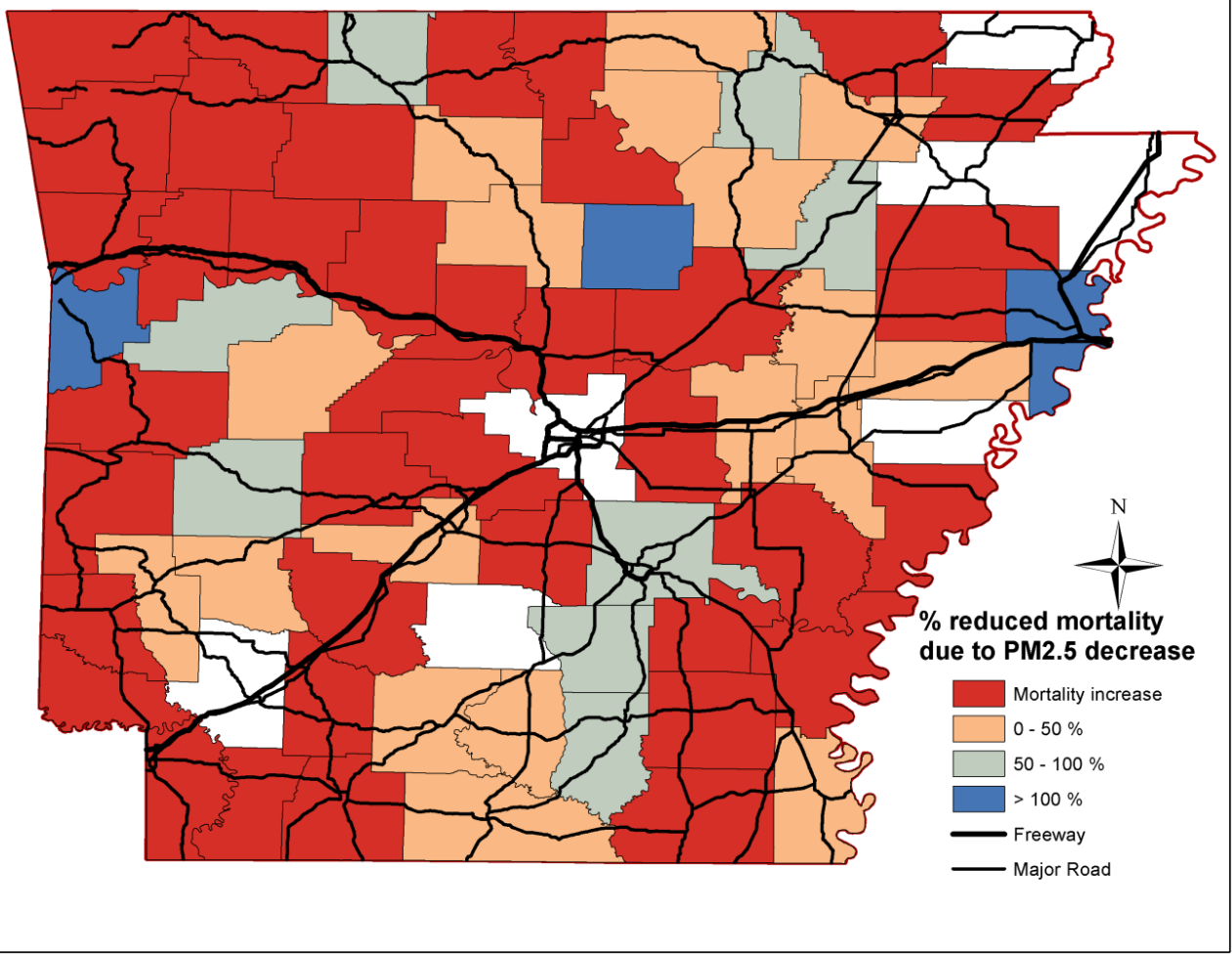


The improvements in $\mathrm{PM}_{2.5}$ mass concentrations prevented the vast majority of premature deaths due to stroke throughout Arkansas, especially in the farming communities along the Delta region (eastern/southeast Arkansas). Less than $50 \%$ of the prevented lung cancer deaths were due to lower $\mathrm{PM}_{2.5}$ levels. The decline in non-accidental, cardiovascular and stroke mortality was due to the reduced and less-severe incidences, while, the efficacy of lung cancer treatment did not improve over the last decades [33].

\section{Discussion}

In this study, we demonstrated the absence of a strong $\mathrm{PM}_{2.5}$ spatial concentration gradient. Slightly higher $\mathrm{PM}_{2.5}$ mass concentrations were measured at populated areas (i.e., Little Rock, Conway, West Memphis and Russellville) due to the increased impacts from traffic and other anthropogenic sources typically present in urban centers. Low $\Delta \mathrm{C}, \Delta \mathrm{C} / \mathrm{Ref}$ and COD values were previously observed for urban areas that are highly impacted by secondary $\mathrm{PM}_{2.5}$ and for ozone, a pollutant that is formed from the oxidation of nitrogen oxides and volatile organic compounds during transport $[28,34]$. In these cases, the spatial uniformity was attributed to long residence times allowing for dispersion and diffusion [28]. In a previous study, we identified that a large fraction of $\mathrm{PM}_{2.5}$ originated from sources outside the state of Arkansas [14]. During winter, ammonium nitrate particles formed during transport of nitrogen oxides from anthropogenic activities in western USA and ammonia from livestock and agriculture in Midwest were observed. On the other hand, sulfate (from $\mathrm{SO}_{2}$ oxidation) and diesel combustion particles from power plants, oil refineries, shipping and oil/natural gas exploration facilities from Gulf Mexico coast and Texas dominated $\mathrm{PM}_{2.5}$ in the summer. These types of secondary aerosol ensure a certain degree of uniformity [28]. While the kriging method lacks the ability to identify short-term hot-spots (i.e., areas with episodic high $\mathrm{PM}_{2.5}$ mass concentrations), alternative approaches such as $\mathrm{PM}_{2.5}$ mass concentration at the nearest monitoring site fail to spatially describe $\mathrm{PM}_{2.5}$ mass concentrations. The use of satellite aerosol optical depth was also suggested; however, the coverage and reliability of these measurements were extremely poor before $2007[35,36]$.

The annual $\mathrm{PM}_{2.5}$ mass levels mildly decreased and remained slightly below the annual ambient air quality national standard (NAAQS) of $15 \mu \mathrm{g} / \mathrm{m}^{3}$ over the 2000-2010 period. The decline was higher for the southern-southeast part of the state and along the Mississippi river valley, a region that was influenced by transport of sulfate and diesel particles emitted from the Gulf of Mexico off-shore and coastal sources. We previously showed that $75 \%$ of $\mathrm{PM}_{2.5}$ reductions were due to sulfate and diesel particles and it was attributed to significant controls of $\mathrm{SO}_{2}$ emissions from coal-fired power plants [14]. On the other hand, reduction of nitrate particles affecting mostly northwest and central Arkansas was less abundant because of the limited controls on ammonia emissions from livestock and agriculture. These results suggested that while there was no significant difference in $\mathrm{PM}_{2.5}$ mass levels across the state of Arkansas, particle types and chemical content in southern/southwest Arkansas may be different than those in central and northwest Arkansas. These trends were also consistent with the spatial and temporal variation of $\mathrm{PM}_{2.5}$ chemical species across the USA [15].

We also demonstrate that the decrease in non-accidental, cardiovascular, stroke and to a lesser extent for lung cancer deaths may be partially attributed to the reduction in annual $\mathrm{PM}_{2.5}$ mass 
concentrations. The decline in cardiovascular and stroke mortality coincided with efforts to control cardiovascular risk factors; however, the effect of specific actions on reduced mortality rates cannot be assessed [37]. The effect of $\mathrm{PM}_{2.5}$ on mortality was more pronounced in the southern and eastern counties than central and northwest counties in Arkansas. In many cases, the benefit of the reduced $\mathrm{PM}_{2.5}$ mass levels exceeded the decrease in deaths suggesting that other risk factors were also declining. On the contrary, the prevalence of a risk factor (i.e., hypertension, smoking or nutrition) was among the highest in the state for counties in which mortality increased. Epidemiological studies consistently determine statistically significant associations between ambient $\mathrm{PM}_{2.5}$ and respiratory and cardiovascular mortality and morbidity, but more importantly, they report different effects for particle types and chemical species. In a recent analysis of mortality and $\mathrm{PM}_{2.5}$ trends in 25 communities from 2000 to 2005, Franklin et al. [38] determined that sulfate $(0.51 \%$ increase), potassium $(0.41 \%$ increase $)$, silicon $(0.41 \%$ increase $)$, aluminium $(0.58 \%$ increase $)$, bromine $(0.38 \%$ increase), nickel $(0.37 \%$ increase), vanadium $(0.28 \%$ increase) were major modifiers of the $\mathrm{PM}_{2.5}$-mortality associations. $\mathrm{Ni}, \mathrm{V}, \mathrm{Br}$ are tracers of oil and gas combustion, while $\mathrm{Al}$ and $\mathrm{Si}$ may be associated with industrial activities and minor quantities of mineral soil particles. For comparison, the effect modifications of nitrate, ammonium and organic particles were $0.04 \%,-0.49 \%$ and $-0.02 \%$. Stronger associations were observed in east USA during spring and summer where sulfate is the largest contributor to $\mathrm{PM}_{2.5}$ than in the west USA. Similarly, the comparison of mortality rates in Seattle and Detroit revealed the important effect of secondary and oil combustion particles [12].

There are several limitations for this assessment. The first one is related to the accuracy of exposures to ambient $\mathrm{PM}_{2.5}$ mass concentrations using county-based averages of gridded $\mathrm{PM}_{2.5}$ estimates based on kriging interpolation of $\mathrm{PM}_{2.5}$ measurements. This approach would be associated with large uncertainties of estimates of daily $\mathrm{PM}_{2.5}$ levels but they are reduced as the averaging period is increased to annual estimates [30]. The use of annual levels was also a better determinant of the effects of chronic $\mathrm{PM}_{2.5}$ exposures to mortality [19]. The second limitation is associated with the representativeness of relative risk estimates for populations with different ethnic, racial and socioeconomic characteristics since most of the epidemiological studies have been done in densely populated urban areas. African-Americans have higher risks of heart disease and stroke than people of other races [3]. The risk of Hispanic and Native Americans for heart disease is also higher than that of Caucasian origin. In addition, exposures to $\mathrm{PM}_{2.5}$ chemical components differed by age, race/ethnicity and socioeconomic status [39]. Here, we used relative risk estimates obtained from large studies that included subjects with demographic characteristics comparable to those in Arkansas and communities near Arkansas (i.e., Memphis, TN and Birmingham, AL, USA).

The findings of this study are also relevant for policy-relevant matters such as they provide strong indications on the benefits of the Clean Air Act and the National Ambient Air Quality Standards (NAAQS) legislations implementation. They also highlight the need to design targeted policies to reduce the burden of the most harmful types of particles on health taking into account regional characteristics. For example, controls on emissions of ammonia and nitrogen oxides would reduce the formation of nitrate particles in winter but have very little effect during summer, because low ambient temperatures are needed for the gas-to-particle partitioning of nitric acid. These borderline but real effects of $\mathrm{PM}_{2.5}$ on reduced mortality are also necessary to provide sufficient lead time for policies and efforts targeting major cardiovascular and stroke risk factors (obesity, hypertension, lack of exercise, 
cholesterol, smoking and health care access) to emerge. For example, meaningful improvements of the obesity rate may be observed between generations rather than within a generation. Similarly, reduction in smoking is typically associated with reduced smoking frequency rather than complete cessation. Advances in medicine and health technologies could only help those who have access to health care, thus reducing their overall effectiveness. It is, therefore, essential to keep making incremental changes in mortality rates by reducing the burden of air pollution and maintain the involvement of policy makers and the public.

\section{Acknowledgments}

This study was partially funded by the UAMS Center for Diversity Affairs Arkansas Commitment Scholars and by the Translational Research Institute (TRI), grant UL1TR000039 through the NIH National Center for Research Resources and National Center for Advancing Translational Sciences. The content is solely the responsibility of the authors and does not necessarily represent the official views of the NIH.

\section{Author Contributions}

Marie-Cecile G. Chalbot obtained, analyzed and interpreted the data, and wrote the manuscript. Tamara A. Jones assisted in analysis of air pollution data, Ilias G. Kavouras conceptualized the study, supervised the data analysis and wrote the manuscript.

\section{Conflicts of Interest}

The authors declare no conflict of interest.

\section{References}

1. Mujib, M.; Zhang, Y.; Feller, M.A.; Ahmed, A. Evidence of a "Heart Failure Belt" in the southeastern United States. Amer. J. Cardiol. 2011, 107, 935-937.

2. Howard, G. Why do we have a stroke belt in the southeastern United States? A review of unlikely and uninvestigated potential causes. Amer. J. Med. Sci. 1999, 317, 160-167.

3. Maulden, J.; Philips, M.M. 2012 Arkansas Heart Disease and Stroke Report-A Snapshot of Cardiovascular Diseases IN Arkansas; Arkansas Minority Health Commission: Little Rock, AR, USA, 2012.

4. Balamurugan, A.; Mehta, P.; Bates, J.; Mehta, J.L. Change in mortality from coronary heart disease and stroke in Arkansas (1979 to 2007). Amer. J. Cardiol. 2011, 107, 156-160.

5. McClure, L.A.; Murphy, H.L.; Roseman, J.; Howard, G.; Malarcher, A. Regional and racial differences in smoking and exposure to secondhand smoke: The reasons for geographic and racial differences in stroke (REGARDS) study. Prev. Chronic Dis. 2011, 8. Available online: http://www.cdc.gov/pcd/issues/2011/sep/pdf/10_0190.pdf (accessed on 5 June 2014).

6. Peel, J.; Tolbert, P.; Klein, M.; Metzger, K.; Flanders, W.; Todd, K.; Mulholland, J.; Ryan, P.; Frumkin, H. Ambient air pollution and respiratory emergency department visits. Epidemiology 2005, 16, 164-174. 
7. Zanobetti, A.; Schwartz, J. The effect of particulate air pollution on emergency admissions for myocardial infarction: A multicity case-crossover analysis. Environ. Health Perspect. 2005, 113, 978-982.

8. Dominici, F.; Peng, R.; Bell, M.; Pham, L.; McDermott, A.; Zeger, S.; Samet, J. Fine particulate air pollution and hospital admission for cardiovascular and respiratory diseases. JAMA 2006, 295, 1127-1134.

9. Ostro, B.; Broadwin, R.; Green, S.; Feng, W.; Lipsett, M. Fine particulate air pollution and mortality in nine California counties: Results from CALFINE. Environ. Health Perspect. 2006, 114, 29-33.

10. Crouse, D.L.; Peters, P.A.; van Donkelaar, A.; Goldberg, M.S.; Villeneuve, P.J.; Brion, O.; Khan, S.; Atari, D.O.; Jerrett, M.; Pope, C.A.; et al. Risk of non accidental and cardiovascular mortality in relation to long-term exposure to low concentrations of fine particulate matter: A Canadian national-level cohort study. Environ. Health Perspect. 2012, 120, 708-714.

11. Turner, M.C.; Krewski, D.; Pope, C.A., III; Chen, Y.; Gapstur, S.M.; Thun, M.J. Long-term ambient fine particulate matter air pollution and lung cancer in a large cohort of never-smokers. Amer. J. Respir. Crit. Care Med. 2011, 184, 1374-1381.

12. Zhou, J.; Ito, K.; Lall, R.; Lippmann, M.; Thurston, G. Time-series analysis of mortality effects of fine particulate matter components in Detroit and Seattle. Environ. Health Perspect. 2011, 119, 461-466.

13. Wellenius, G.A.; Burger, M.R.; Coull, B.A.; Schwartz, J.; Suh, H.H.; Koutrakis, P.; Schlaug, G.; Gold, D.R.; Mittleman, M.A. Ambient air pollution and the risk of acute ischemic stroke. Arch. Intern. Med. 2012, 172, 229-234.

14. Chalbot, M.-C.; McElroy, B.; Kavouras, I.G. Sources, trends and regional impacts of fine particulate matter in southern Mississippi Valley: Significance of emissions from sources in the Gulf of Mexico coast. Atmos. Chem. Phys. 2013, 13, 3721-3732.

15. Bell, M.L.; Dominici, F.; Ebisu, K.; Zeger, S.L.; Samet, J.M. Spatial and temporal variation in $\mathrm{PM}_{2.5}$ chemical composition in the United States for health effects studies. Environ. Health Perspect. 2007, 115, 989-995.

16. Krall, J.R.; Anderson, G.B.; Dominici, F.; Bell, M.L.; Peng, R.D. Short-term exposure to particulate matter constituents and mortality in a national study of U.S. urban communities. Environ. Health Perspect. 2013, 121, 1148-1153.

17. Spak, S.N.; Holloway, T. Seasonality of speciated aerosol transport over the great lakes region. J. Geophys. Res.-Atmos. 2009, 114, doi:10.1029/2008JD010598.

18. Ballester, F.; Medina, S.; Goodman, P.; Boldo, E.; le Tertre, A.; Neuberger, M.; Larrieu, S.; Kuenzli, N.; Cambra, K.; Katsouyanni, K.; et al. Health impact assessment on the benefits of reducing $\mathrm{PM}_{2.5}$ using mortality data from 28 European cities. Epidemiology 2006, 17, S248-S248.

19. Boldo, E.; Medina, S.; LeTertre, A.; Hurley, F.; Muecke, H.-G.; Ballester, F.; Aguilera, I. Apheis: Health impact assessment of long-term exposure to $\mathrm{PM}_{2.5}$ in 23 European cities. Eur. J. Epidemiol. 2006, 21, 449-458.

20. Sheffield, P.E.; Knowlton, K.; Carr, J.L.; Kinney, P.L. Modeling of regional climate change effects on ground-level ozone and childhood asthma. Amer. J. Prev. Med. 2011, 41, 251-257. 
21. World Health Organization. Evaluation and Use of Epidemilogical Evidence for Environmental Health Risk Assessment; WHO Regional Office for Europe: Copenhagen, Denmark, 2000; p. 39.

22. World Health Organization. Quantification of Health Effect of Exposure to Air Pollution; WHO Regional Office for Europe: Copenhagen, Denmark, 2001; p. 34.

23. Pope, C.A.I.; Burnett, R.T.; Thun, M.J.; Calle, E.E.; Krewski, D.; Ito, K. Lung cancer, cardiopulmonary mortality, and long-term exposure to fine particulate air pollution. JAMA 2002, 287, 1132-1141.

24. Krewski, D.; Burnett, R.; Jerrett, M.; Pope, C.; Rainham, D.; Calle, E.; Thurston, G.; Thun, M. Mortality and long-term exposure to ambient air pollution: Ongoing analyses based on the American cancer society cohort. J. Toxicol. Environ. Health Pt. A 2005, 68, 1093-1109.

25. Krewski, D.; Jerrett, M.; Burnett, R.T.; Ma, R.; Hughes, E.; Shi, Y.; Turner, M.C.; Pope, C.A., III; Thurston, G.; Calle, E.E.; et al. Extended Follow-up and Spatial Analysis of the American Cancer Society Study Linking Particulate Air Pollution and Mortality; Health Effects Institute: Boston, MA, USA, 2009. Available online: http://pubs.healtheffects.org/getfile.php?u=478 (accessed on 21 April 2014).

26. Franklin, M.; Zeka, A.; Schwartz, J. Association between $\mathrm{PM}_{2.5}$ and all-cause and specific-cause mortality in 27 USA communities. J. Expo. Sci. Environ. Epidemiol. 2007, 17, 279-287.

27. Jaffe, D.; Ray, J. Increase in surface ozone at rural sites in the western USA. Atmos. Environ. 2007, 41, 5452-5463.

28. Pinto, J.; Lefohn, A.; Shadwick, D. Spatial variability of $\mathrm{PM}_{2.5}$ in urban areas in the United States. J. Air Waste Manage. Assoc. 2004, 54, 440-449.

29. Lianou, M.; Chalbot, M.; Kotronarou, A.; Kavouras, I.G.; Karakatsani, A.; Katsouyanni, K.; Puustinnen, A.; Hameri, K.; Vallius, M.; Pekkanen, J. et al. Dependence of home outdoor particulate mass and number concentrations on residential and traffic features in urban areas. J. Air Waste Manage. Assoc. 2007, 57, 1507-1517.

30. Gulliver, J.; de Hoogh, K.; Fecht, D.; Vienneau, D.; Briggs, D. Comparative assessment of gIS-based methods and metrics for estimating long-term exposures to air pollution. Atmos. Environ. 2011, 45, 7072-7080.

31. Liao, D.; Peuquet, D.J.; Duan, Y.; Whitsel, E.A.; Dou, J.; Smith, R.L.; Lin, H.; Chen, J.; Heiss, G. GIS approaches for the estimation of residential-level ambient PM concentrations. Environ. Health Perspect. 2006, 114, 1374-1380.

32. Pearce, J.L.; Rathbun, S.L.; Aguilar-Villalobos, M.; Naeher, L.P. Characterizing the spatiotemporal variability of $\mathrm{PM}_{2.5}$ in Cusco, Peru using Kriging with external drift. Atmos. Environ. 2009, 43, 2060-2069.

33. Reeve, G.R.; Balamurugan, A.; Simon, W.; Faulker, L.; Zohoori, N. The Burden of Heart Disease \& Stroke in Arkansas; Arkansas Department of Health: Little Rock, AR, USA, 2012; pp. 1-94.

34. Kavouras, I.G.; DuBois, D.W.; Etyemezian, V.; Nikolich, G. Spatiotemporal variability of ground-level ozone and influence of smoke in treasure valley, Idaho. Atmos. Res. 2013, 124, 44-52.

35. Kumar, N.; Chu, A.D.; Foster, A.D.; Peters, T.; Willis, R. Satellite remote sensing for developing time and space resolved estimates of ambient particulate in Cleveland, OH, USA. Aerosol Sci. Tech. 2011, 45, 1090-1108. 
36. Lee, S.; Serre, M.L.; van Donkelaar, A.; Martin, R.V.; Burnett, R.T.; Jerrett, M. Comparison of geostatistical interpolation and remote sensing techniques for estimating long-term exposure to ambient $\mathrm{PM}_{2.5}$ concentrations across the continental United States. Environ. Health Perspect. 2012, 120, 1727-1732.

37. Lackland, D.T.; Roccella, E.J.; Deutch, A.F.; Fornage, M.; George, M.G.; Howard, G.; Kissela, B.M.; Kittner, S.J.; Lichtman, J.H.; Lisabeth, L.D.; et al. Factors influencing the decline in stroke mortality: A statement from the American heart association/American stroke association. Stroke 2014, 1, doi:10.1161/01.str.0000437068.30550.cf.

38. Franklin, M.; Koutrakis, P.; Schwartz, J. The role of particle composition on the association between $\mathrm{PM}_{2.5}$ and mortality. Epidemiology 2008, 19, 680-689.

39. Bell, M.L.; Ebisu, K. Environmental inequality in exposures to airborne particulate matter components in the United States. Environ. Health Perspect. 2012, 120, 1699-1704.

(C) 2014 by the authors; licensee MDPI, Basel, Switzerland. This article is an open access article distributed under the terms and conditions of the Creative Commons Attribution license (http://creativecommons.org/licenses/by/3.0/). 